DIW BERLIN

Discussion Papers
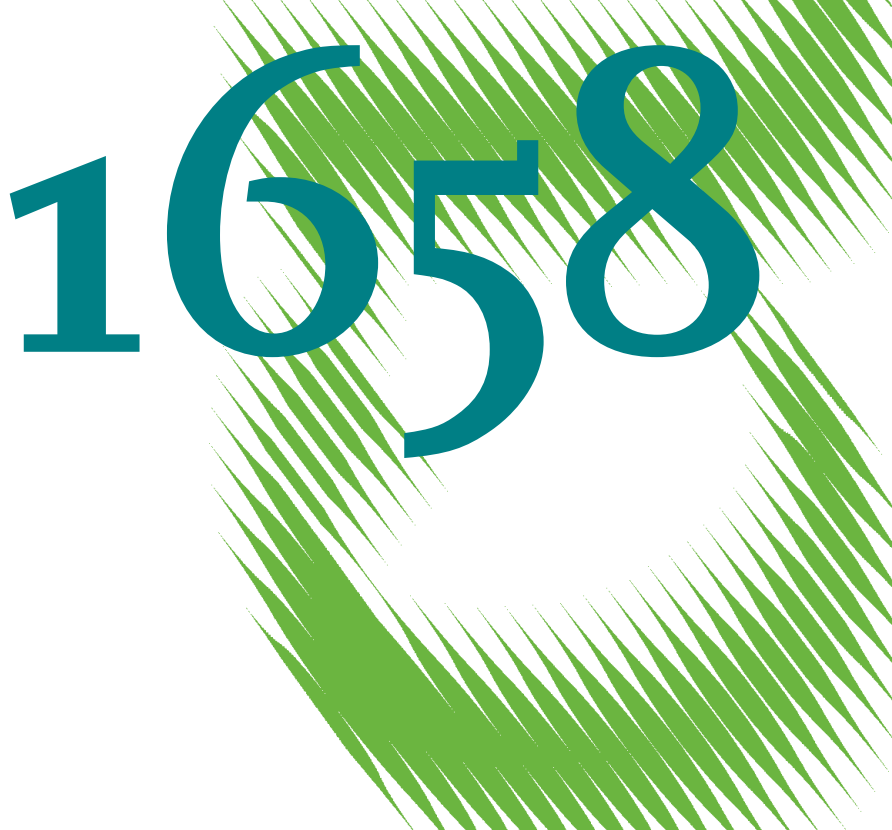

Do Women in Highly Qualified Positions Face Higher Work-to-Family Conflicts in Germany than Men? 
Opinions expressed in this paper are those of the author(s) and do not necessarily reflect views of the institute.

IMPRESSUM

(C) DIW Berlin, 2017

DIW Berlin

German Institute for Economic Research

Mohrenstr. 58

10117 Berlin

Tel. +49 (30) $89789-0$

Fax +49 (30) $89789-200$

http://www.diw.de

ISSN electronic edition 1619-4535

Papers can be downloaded free of charge from the DIW Berlin website:

http://www.diw.de/discussionpapers

Discussion Papers of DIW Berlin are indexed in RePEc and SSRN:

http://ideas.repec.org/s/diw/diwwpp.html

http://www.ssrn.com/link/DIW-Berlin-German-Inst-Econ-Res.html 


\title{
Do Women in Highly Qualified Positions Face Higher Work-To-Family Conflicts in Germany than Men?
}

\author{
Anne Busch-Heizmann*
}

\author{
Elke Holst ${ }^{\dagger}$
}

\begin{abstract}
Changing employment conditions lead to new chances, but also new risks for employees. In the literature, increasing permeability between occupational and private life is discussed as one special outcome of this development that employees must face, especially those in highly qualified positions. Drawing on existing research, we investigate in how far women and men in those positions differ in their perceived work-to-family conflicts (WFC), considering the mediating role of gender specific job opportunities. Referring conflicting theoretical arguments, we hypothesize that in Germany - as a conservative welfare state - women, especially those with family responsibilities, will perceive higher WFC than men in those positions. Our analysis is based on data from the German Socio-Economic Panel Study (SOEP). Using the Siegrist instrument on effort-reward imbalance we find that women in highly qualified positions perceive higher WFC than men. This association is explained by women's lower willingness to take risks, and also party explained by lower job rewards women receive. It gets visible even more strongly if women's lower time-based burdens in the job are controlled for. Mixed results are observed concerning associations between family responsibilities and WFC, which is in line with ambivalent results in the literature.
\end{abstract}

Keywords: Work-to-family conflict, highly qualified positions, managers, gender, SOEP

JEL Classification: I3, B54, M1

\footnotetext{
* Corresponding author: Prof. Dr. Anne Busch-Heizmann, Address: Universität Duisburg Essen, Fakultät für Gesellschaftswissenschaften, Institut für Soziologie, Sekretariat II, LF 354, Lotharstr. 65, 47057 Duisburg, Germany, email: anne.busch-heizmann@uni-due.de,_Phone:+49 2033792451

${ }^{\dagger}$ PD Dr. Elke Holst, DIW Berlin and Europa Universität Flensburg, Address:DIW Berlin, Mohrenstraße 58, D-10117 Berlin, Germany, email: eholst@diw.de,Phone:+49 30 89789-281
} 



\section{Introduction}

In modern labor markets, we observe changing forms of employment and employment conditions, resulting from societal, technological, sectoral, and global developments, leading to the increasing permeability of boundaries between private and occupational spheres (Sauer, 2012). On the one hand, this new flexibility might reduce conflicts between family and work due to increased flexibility in location and organization of working time. On the other hand, these changes might result in more conflicts as boundaries between work and family blur. The conflict aspect is gaining more and more research interest. Due to an increasing permeability of the boundaries between the life spheres of "occupational work" and "private life," managing obligations in both domains is increasingly complex and the resulting conflicts can be seen as one important and increasing problem in modern societies (Schiemann et al., 2006; Voß, 1998). In the German research, this is discussed in connection with the emergence of a new “entreployee," (Arbeitskraftunternehmer) where the employee structures and controls their own occupational work more and more independently from external organizational structures and formalizations (Pongratz \& Voß, 2003). Conflicts between occupational work and private life have a high societal relevance, since they are associated with negative subjective outcomes, including physical and mental health (e.g. Allen \& Armstrong, 2006; Allen et al., 2000; see for an overview of empirical findings Cullati, 2014).

In existing research it is expected that these kinds of conflicts are particularly high for employees in higher positions within the labor market (e.g., Kotthoff, 2001). Additionally, it can be asked if women and men in higher positions differ in their perception of this expected permeability between occupational and private sphere, with women having higher role conflicts between both parts of life, due to gender roles in 
modern societies that often still foster the male breadwinner model and different gender roles for women and men (for the US labor market, see Schiemann et al., 2006). Concerning the German context, we expect that possible role conflicts, resulting in high work-to-family conflicts may be especially high, in particular for women, since Germany is a relatively conservative welfare state (Esping-Andersen, 1990) with a relatively traditional “gender culture” (Pfau-Effinger, 1998).

To sum up, in this article we investigate work-to-family conflicts as an important health-related pressure within modern labor markets with a special focus on highly qualified positions (including extensive managerial positions) in Germany. We ask to what extent this pressure is a special problem for women, especially those with family responsibilities, in those positions, as compared to men, in Germany. Finally we also investigate the mediating role of job rewards and job opportunities for the possible gender gap in work-to-family conflicts. ${ }^{1}$

\section{Theoretical background, state of research and hypotheses}

\section{Measuring work-to-family conflicts (WFC)}

In psychological research, work-to-family-conflicts are defined as "form of inter-role conflict in which the role pressures from the work and family domains are mutually incompatible in some respect” (Greenhaus \& Beutell, 1985, p. 77). However, this concept also includes general conflicts in the private sphere that are independent of family responsibilities (e.g. leisure activities). Therefore, individuals without a family can also have work-to-family-conflicts or, as other research labels it, "work-nonworkspillover” (Greenhaus \& Parasuraman, 1987). This goes also in line with research, showing, on the one hand, that family responsibilities do not always increase WFC and, on the other hand, that also people without children perceive the reconciliation between 
occupational and private life as a challenge (e.g., Ahmad et al., 2013). Parents may already be developed strategies to help them to handle permeability between both life spheres. So when we talk about work-to-family-conflicts (WFC), this also includes persons without actual family responsibilities.

In the literature, three types of WFC are defined (Greenhaus \& Beutell, 1985): timebased conflicts include those conflicts arising when time-related demands in one sphere do not fit with time-related demands in the other sphere. Strain-based conflicts mean those conflicts due to stress reactions coming from demands in the one sphere that lowers the performance in the other sphere. Those demands include time demands, but also others like low social support at the workplace, task ambiguity, and physical demands. Behavior-based conflicts mean that demands on particular role behavior in one sphere (e.g., aggressiveness, rationality) stand contrary to role demands in the other sphere (e.g., emotionality, warmth).

As our empirical design will show, we focus on strain-based and behavior-based conflicts; in essence, the more cognitive component of WFC, which can be measured best with subjective indicators. As the literature stresses, subjective indicators are seen as particularly important for analyzing WFC appropriately (McGinnity \& Calvert, 2009, p. 496). Time-based conflicts will serve as control variables in our models, to show the net effects of our independent variables on the cognitive WFC. In other words, we want to analyze strain- and behavior-based conflicts, controlled for the "explained sources" of WFC in the form of time-related efforts.

WFC in highly qualified positions

Our paper focuses on the extent of WFC in higher qualified occupational positions. Here, problems of low work-family compatibility can be expected to be especially prevalent, since in those positions work content is less structured and at the same time 
highly complex and (time-)demanding and, therefore, require high flexibility and selfdependency. At the same time, it can be expected that these individuals have especially high subjective expectations on the quality of their job and its content. Therefore, the literature on this "new” problem in modern labor markets stresses highly qualified workers as an especially problematic group that is confronted with these problems to a large extent and to have a high potential for "self-exploitation” (Baethge et al., 1995; Kotthoff, 2001; Moosbrugger, 2012; Schiemann et al., 2006). Schiemann et al. (2006, p. 243) calls this assumption "stress of higher status hypothesis," meaning that higher positions include several working conditions (e.g., long work hours, flexibility, as well as permeability between work and private spheres) that are costly for the workers. This means they have also a high potential for WFC (see also Schieman \& Glavin, 2016) although more resources in high positions can also be expected to reduce negative outcomes (ibid., see below).

In several western countries, WFC is stronger in higher as compared to lower occupational positions (McGinnity \& Calvert, 2009; Schiemann et al., 2006; M. White et al., 2003), including in Germany (McGinnity \& Calvert, 2009), and part of this association remains significant even after controlling for work hours and time-pressure (ibid.) - in other words, when controlling for sources of time-based conflicts. The latter study also shows that this higher work involvement among professionals is mostly not a voluntary "choice": Most of these full time working people desire fewer work hours (see for similar results in Germany Holst et al., 2015).

WFC in highly qualified positions and the significance of gender

The question we are interested in is if women and men in highly qualified positions are confronted differently with WFC. First, one could expect higher WFC for women than for men. Gender role socialization arguments assume that women and men have 
internalized different assumptions regarding appropriate behavior and competences (Correll, 2004; Eccles, 1987; Marini \& Brinton, 1984). Family- and private-related orientations, competences, and expectations are more frequently assigned to women, while work- and career-related orientations more assigned to men. These assignments are somewhat internalized by the individuals, which influences their behavior and expectations. This can lead to particularly strong perceived role conflicts for women in the labor market, especially in highly qualified positions, since here the job requirements correspond mainly to role expectations appropriate for men (Eagly, 2003; Ridgeway, 2001). In line with these assumptions, Pudrovska and Karraker (2014) show for the US that women, but not men, show stronger depressive symptoms the more job authority they have. Schieman et al. (2006, p. 245) call this the "traditional role balance” perspective, and the assumed mechanisms should result in higher WFC for women as compared to men in highly qualified positions.

However, contrary to those arguments, one could also expect that women and men do not differ in their WFC in highly qualified positions, or that women may perceive even lower WFC than men. Beside the above-mentioned changes in the labor market, we observe changes concerning the role of women and men in our society (Behnke \& Meuser, 2003): traditional gender arrangements are more and more challenged, and the employment work and career of women are more and more aspired in the society as well as by the women themselves. This may lead to advantages for women, especially in highly qualified positions. Schiemann et al. (2006, p. 245) labels this assumption as "egalitarian role balance" argument, meaning that in high occupational positions egalitarian gender roles dominate and not only men, but also women have high expectations for their partner concerning the share of family responsibilities and housework. Therefore, stressful job situations, resulting in high WFC, should be similar for men and women in high occupational positions. Furthermore, other research 
interprets multiple role responsibilities for women as an advantageous resource. For example, Frey (2004) hypothesizes that the requirements of the new “entreployee” (see above) can be fulfilled best by women, at least by those who work in high positions. Since women have special experiences with discontinuity due to family obligations and double burdens, they are better able to organize their time, structure their schedules, and combine conflicting demands from different life spheres. In other words: "women managers may have more developed strategies for dealing with the conflicts of work and family roles than the men managers“ (Apperson et al., 2002, p. 14).

At the same time however, this - at least to some extent - observed egalitarianism in the labor market is not visible to the same extent within the family. This can be explained by labor market and family related institutions that still foster the male-breadwinner model, but also by gendered “cultures," meaning gender roles in values and norms concerning the appropriate roles of men and women in our society that are not easy to change. To be more concrete, the "doing gender" approach assumes that in modern societies, some social arrangements exist that reproduce gender-specific roles and identities (West \& Zimmerman, 1987). One of these arrangements is the division of family work. Bertrand et al. (2015) found for the US that wives who actually have a higher income than their husbands mitigate the reversal of gender roles by increasing their contribution of housework activities. It is argued that, although in the labor market women have more and more chances to participate, forwarded by economic pressures and skill shortages, this "violation" of traditional gender roles is compensated with an even reinforced traditionalization in other life domains, e.g., in the house- and family work (Brines, 1994). Although some progress can also be observed here as well, in Germany, women with a family are still more responsible for house- and family- work, even when they are employed (Busch-Heizmann \& Bröckel, 2015; Peuckert, 2012) and when they are in highly qualified positions (Holst et al., 2015). 
Behnke and Meuser (2003) point out that in dual career couples, although a traditional male-breadwinner model no longer exists, one can observe new forms of the division of labor, that is, a "Vereinbarkeitsmanagement" (the management of reconciling family and work) that is performed mainly by the women. Women in those partnerships, especially when they have children, make a strong effort to organize and rationalize the everyday daily routines not only within the job, but also in their private life. Therefore, although women with family responsibilities who climbed the hierarchical ladder may have found strategies for a more efficient work organization, this additional time management may lead to additional stress. In addition, women without family responsibilities in highly qualified positions may feel within interactions at work that they do not behave appropriately concerning their cultural gender norms. Therefore, they may put more effort into strategies to fulfill both their "female“ gender identity and their authority role at the workplace, leading to additional stress.

In line with those conflicting arguments concerning gender differences in WFC in highly qualified positions, the existing international empirical results are mixed. In the US, female managers have higher WFC than male managers, but the effects are relatively small (Apperson et al., 2002). In Canada, no differences between women and men in high status occupations concerning WFC can be observed (Schiemann et al., 2006). Another study for the US shows that for female managers, multiple role responsibilities is positively associated with life satisfaction, self-esteem, and selfacceptance - the important moderator here is the extent to which the women are supported by their family (Ruderman et al., 2002).

WFC in highly qualified positions and the significance of gender: The German context It may be that differences in WFC between women and men in highly qualified positions to the disadvantage of women can be observed more clearly when observing 
the German context. Research stresses that in Germany a relatively traditional "gender arrangement” still exists, as compared to other welfare states (Pfau-Effinger, 1998). Here, cultural normative expectations for being a "good mother" are still relatively high and parenting is still relatively strong in the private responsibility. Germany scores, for example, very high on the masculinity dimension in Hofstede's cultural framework. ${ }^{2}$ More than 50 percent in (West) Germany agree with statements like, "If a woman earns more than her husband, it's almost certain to cause problems” (US: less than 40 percent) (Wieber \& Holst, 2015). Therefore, violations against the appropriate role for women may produce particularly high problems for women in highly qualified positions in Germany, also in terms of WFC, as compared to other welfare states. This may already be visible for women without family responsibilities, but especially strong for women with family responsibilities, since those women do not only violate against the role of a "good woman”, but also against the role of a "good mother."

From those assumptions, we extract the following hypothesis for persons in highly qualified positions in Germany:

In highly qualified positions in Germany,

H1: $\quad$ women show higher WFC than men,

H2: women with family responsibilities have the highest WFC as compared to women without family responsibilities and men.

WFC in and the significance of gender - mediator "job rewards"

German studies underline that in highly qualified positions, we find a tendency of a “voluntary self-exploitation” (Kotthoff, 2001; Moosbrugger, 2012). Although work pressures are relatively high, people in those positions show a high intrinsic motivation and identification with the job, more possibilities to compensate effort, and are highly esteemed in the firm they work for. ${ }^{3}$ This is also called "resources of higher status 
hypothesis” (Schiemann et al., 2006, p. 244), predicting that high status positions are not only characterized by high efforts, but also high resources that buffer potential WFC.

Here, it can be assumed that women in highly qualified positions profit to a lower extent than men from this positive resource or "counter pole". Those women are often numerical minorities and may suffer from this so-called "token" status in terms of social exclusion at work (Kanter, 1977), and are confronted with stereotypical competence and performance expectations (Ridgeway, 2001). This may lead to various forms of discrimination. Therefore, part of the puzzle of higher WFC for women than for men in highly qualified positions may be explained by lower positive resources women receive. From these considerations we expect the following hypothesis:

H3: $\quad$ Gender differences in WFC can be explained partly (but not fully) with lower job rewards women receive.

WFC in highly qualified positions and the significance of gender - mediator "job opportunities”

The amount of WFC partly depends on job opportunities to reconcile work and family (Bellavia \& Frone, 2005, p. 127). Therefore, another control dimension that has to be controlled in the models when analyzing gender differences in WFC, is that women and men are embedded in different structures in the labor market that offer different conditions to reconcile occupational work and private life. This includes the selection of women and men in different occupations and organizations, which is also visible in highly qualified positions. Here, women work more often in small firms, in the public sector, and in so-called “women's occupations” than men (Holst et al., 2015). It can be expected that in these contexts, reconciliation opportunities are higher than in large 
firms, the private sector, and "men's occupations." 4 In parallel, women in highly qualified positions have shorter work hours on the job as compared to men in those positions on average (ibid.). Therefore, the potential of time-based conflicts as part of WFC, that also at least partly influences strain- and behavior-based conflicts, can be expected to be somewhat weaker for women.

In other words, the gender gap in WFC may be underestimated if different contexts (with different reconciliation opportunities) are not controlled for in the models.

Thus, we assume the final hypothesis:

H4: Gender differences in WFC get visibly stronger when controlling for job opportunities, i.e., (a) organizational and occupational characteristics and (b) time-based burdens in the job.

\section{Data, variables, and methods}

Data

The models are based on data from the German Socio-Economic Panel Study, version 31 (SOEP v.31) (Wagner et al., 2007). Started in 1984, the SOEP is a wide-ranging representative longitudinal study of private households, based at the German Institute for Economic Research, DIW Berlin. It includes nearly 11,000 households, and about 30,000 persons. The most recent available wave is for the year 2014. Since information regarding WFC and other information is asked for twice, we use only the 2006 and 2011 waves for our analysis.

The sample observed consists of persons in highly qualified positions defined as whitecollar employees with extensive managerial duties (e.g., managing director, manager, head of a large firm or concern) or with managerial function or highly qualified duties (e.g., scientist, attorney, head of department). We take only persons in the main 
employment age (25 to 54 years) and those working full-time ( $\geq 35$ hours per week), since we assume the labor market changes with increasing flexibility and permeability described above to be particularly prevalent in this group.

\section{Variables}

Besides the sex category of the respondent (woman or man), the central variable is work-to-family conflict (WFC). Here we use variables from the short instrument of the effort-reward imbalance scale by Siegrist, asked in the SOEP in the years 2006 and 2011 (Siegrist et al., 2008). To be more specific, we use indicators that measure the dimension "over-commitment." Here, several questions are surveyed that can be interpreted as work-family conflict; that is, information showing how difficult it is for people to disconnect from work when they are at home (for a comparable operationalization, see McGinnity \& Calvert, 2009). Thus, our measurement can be linked with the concept of what is called permeability in the literature adequately. To be more concrete, our measurement shows the cognitive component of WFC, the cognitive irritation, or, how it is often called, rumination. Therefore, as we already mentioned, we focus on the strain- and behavior-based conflicts as part of WFC, whereas time-based sources of conflict serve as control variables. To be more concrete, we use the following questions:

- “I often am already thinking about work-related problems when I wake up" (Strongly disagree, disagree, agree, strongly agree),

- "When I come home, it is very easy to switch off from thinking about work" (scale reversed),

- "Work seldom lets go of me; it stays in my head all evening”,

- " "If I put off something that needs to be done that day, I can't sleep at night”. 
From these variables, a sum index is constructed. Subsequently, we transformed the items (subtracting the minimum and dividing by the maximum value), so that they ranged between 0 and 1 . High values indicate high, low values indicate low WFC.

To get the associations net of the positive resources in form of job rewards offered in highly qualified positions and that compensate for work pressures, which may underestimate the associations (Hypothesis 3), we also include information on job rewards into our models. Here, we created three sum indices (ranging between 0 for lowest rewards and 1 for highest rewards, see above) indicating the job reward people receive at work (Siegrist et al., 2008):

\section{Esteem:}

- "I receive the recognition I deserve from my superiors" (no and burdens very heavily, no and burdens heavily, no and somewhat burdens, no and burdens not at all, yes),

- "When I consider all my accomplishments and efforts, the recognition of I've received seems fitting”.

Job security:

- "My job is in jeopardy” (yes and burdens very heavily, yes and burdens heavily, yes and somewhat burdens, yes and burdens not at all, no),

- “I am undergoing - or I expect to undergo - a worsening in my working situation”. Job promotion opportunities

- “The chances of promotion in my company are bad” (yes and burdens very heavily, yes and burdens heavily, yes and somewhat burdens, yes and burdens not at all, no),

- When I consider all my accomplishments and efforts, my chances of personal advancement seem fitting (no and burdens very heavily, no and burdens heavily, no and somewhat burdens, no and burdens not at all, yes),

- When I think about all my accomplishments, my pay seems appropriate. 
To show our assumed associations are free from allocations of men and women in different parts of the labor market with different opportunities to reconcile occupational work and private life (Hypothesis 4), we control for time-based burdens in the job (that is, the part of WFC that is due to time-based conflicts), as well as firm and occupational characteristics:

For time-based burdens on the job, we include actual weekly work hours, as well as the part of the instrument of Siegrist that measures job efforts (sum index, ranging between 0 for lowest efforts and 1 for highest efforts, see above):

- I am often interrupted and distracted while working (no, yes and burdens not at all, ..., yes and burdens very heavily),

- Because of the high volume of work, there is often high time pressure,

- The amount of work has increased steadily over the last two years.

For firm characteristics, we include firm size, economic industry, and whether it is public or private sector. As occupational characteristics, we include the information if people work in typical "women's occupations" (70-100 percent women in the current occupation, “men's occupation (0-30 percent women in the current occupation), or gender-balanced occupations (remaining occupations) - that is, information on horizontal occupational sex segregation (Jacobs, 1989). This variable is computed by taking the year-specific gender composition in each occupation of the job classification of the German Federal Office of Statistics (3-digit), version 1992 (Federal Statistical Office, 1992) from a special evaluation of the German Microcensus (Federal Statistical Office, 2012) for the years 2006 and 2011 conducted by the German Federal Office of Statistics, via the job classification to the SOEP.

To capture vertical occupational sex segregation, we include the information on whether the person performs extensive managerial duties or managerial functions/highly qualified duties. 
To capture family responsibilities we take two variables into account: Firstly, we include the family status. Secondly, we account for the information if the youngest child in the household is under 7 years old.

Women in highly qualified positions may be a strongly selected group of persons, since those women who succeeded in the labor market despite all barriers (i.e., "glass ceiling”) may be “special” highly motivated women. Therefore, job burdens may be underestimated for women. To capture such a selection effect, we include a measurement of personality traits; specifically the willingness to take risks (Fietze et al., 2011).

We also include several structural control variables into the models, that is, age, living in eastern or western Germany, being highly educated, ${ }^{5}$ and the years of observation (2006 or 2011). Table 1 provides an overview over the included variables and their descriptives.

\section{Methods}

For our multivariate models, we run linear OLS-regressions. Since we have a pooled model with two years of information, we estimate a cluster regression, with robust standard errors that correct for correlation of person specific information (Huber, 1967; H. White, 1980). Firstly, we analyze differences between women and men in WFC, controlling for several independent variables stepwise, with both women and men in the sample. Secondly, we also run these models for determinants of WFC separately for women and men, to see if there are differences for women and men in the effects of the independent variables. 
Table 1: Full-time employees in highly qualified positions in main employment age: Summary statistics

\begin{tabular}{|c|c|c|c|c|c|c|c|c|}
\hline & \multicolumn{4}{|c|}{$\begin{array}{c}\text { Women } \\
N=637\end{array}$} & \multicolumn{4}{|c|}{$\begin{array}{c}\text { Men } \\
N=1656\end{array}$} \\
\hline & Mean & Std.Dev. & Min. & Max. & Mean & Std.Dev. & Min. & Max. \\
\hline Work-to Family conflict & 0.46 & 0.22 & 0 & 1 & 0.44 & 0.21 & 0 & 1 \\
\hline \multicolumn{9}{|l|}{ Structural characteristics } \\
\hline \multicolumn{9}{|l|}{ Education (share) } \\
\hline Higher education & 0.70 & - & 0 & 1 & 0.67 & - & 0 & 1 \\
\hline Lower Education & 0.30 & - & 0 & 1 & 0.33 & - & 0 & 1 \\
\hline Age & 40.65 & 8.44 & 25 & 54 & 42.09 & 7.37 & 25 & 54 \\
\hline \multicolumn{9}{|l|}{ Region (share) } \\
\hline Eastern Germany & 0.31 & - & 0 & 1 & 0.18 & - & 0 & 1 \\
\hline Western Germany & 0.69 & - & 0 & 1 & 0.82 & - & 0 & 1 \\
\hline \multicolumn{9}{|l|}{ Survey year (share) } \\
\hline 2006 & 0.49 & - & 0 & 1 & 0.52 & - & 0 & 1 \\
\hline 2011 & 0.51 & - & 0 & 1 & 0.48 & - & 0 & 1 \\
\hline \multicolumn{9}{|l|}{ Personal characteristics } \\
\hline Willingness to take risks & 0.48 & 0.20 & 0 & 1 & 0.54 & 0.20 & 0 & 1 \\
\hline \multicolumn{9}{|l|}{ Family characteristics } \\
\hline \multicolumn{9}{|l|}{ Marital status (share) } \\
\hline Married cohabitation & 0.45 & - & 0 & 1 & 0.68 & - & 0 & 1 \\
\hline Other & 0.55 & - & 0 & 1 & 0.32 & - & 0 & 1 \\
\hline \multicolumn{9}{|l|}{ Age of youngest child in household (share) } \\
\hline No child in household & 0.79 & - & 0 & 1 & 0.51 & - & 0 & 1 \\
\hline Child under 7 in household & 0.07 & - & 0 & 1 & 0.23 & - & 0 & 1 \\
\hline Child from 7 to 16 in household & 0.14 & - & 0 & 1 & 0.27 & - & 0 & 1 \\
\hline \multicolumn{9}{|l|}{ Job rewards } \\
\hline Job security & 0.88 & 0.24 & 0 & 1 & 0.89 & 0.23 & 0 & 1 \\
\hline Esteem & 0.79 & 0.28 & 0 & 1 & 0.83 & 0.25 & 0 & 1 \\
\hline Job promotion opportunities & 0.76 & 0.23 & 0 & 1 & 0.79 & 0.23 & 0 & 1 \\
\hline \multicolumn{9}{|l|}{$\begin{array}{l}\text { Firm and occupational } \\
\text { characteristics }\end{array}$} \\
\hline \multicolumn{9}{|l|}{ Economic industry (share) } \\
\hline Other services & 0.69 & - & 0 & 1 & 0.43 & - & 0 & 1 \\
\hline Manufacturing industry & 0.18 & - & 0 & 1 & 0.44 & - & 0 & 1 \\
\hline Trade, hotels and catering. transport & 0.13 & - & 0 & 1 & 0.13 & - & 0 & 1 \\
\hline \multicolumn{9}{|l|}{ Firm size (share) } \\
\hline 19 or fewer employees & 0.17 & - & 0 & 1 & 0.12 & - & 0 & 1 \\
\hline 20 to 199 employees & 0.23 & - & 0 & 1 & 0.27 & - & 0 & 1 \\
\hline 200 to 1999 employees & 0.30 & - & 0 & 1 & 0.27 & - & 0 & 1 \\
\hline 2000 employees or more & 0.30 & - & 0 & 1 & 0.34 & - & 0 & 1 \\
\hline \multicolumn{9}{|l|}{ Share of women in occupation (share) } \\
\hline Male-dominated occupation & 0.22 & - & 0 & 1 & 0.56 & - & 0 & 1 \\
\hline Mixed-gender occupation & 0.55 & - & 0 & 1 & 0.39 & - & 0 & 1 \\
\hline Female-dominated occupation & 0.23 & - & 0 & 1 & 0.05 & - & 0 & 1 \\
\hline \multicolumn{9}{|l|}{ Occupational duties (share) } \\
\hline Extensive managerial duties & 0.07 & - & 0 & 1 & 0.12 & - & 0 & 1 \\
\hline Managerial functions/highly qualified & 0.93 & - & 0 & 1 & 0.88 & - & 0 & 1 \\
\hline \multicolumn{9}{|l|}{ Sector (share) } \\
\hline Public & 0.34 & - & 0 & 1 & 0.16 & - & 0 & 1 \\
\hline Private & 0.66 & - & 0 & 1 & 0.84 & - & 0 & 1 \\
\hline \multicolumn{9}{|l|}{ Time-based burdens in the job } \\
\hline Actual working hours & 45.34 & 6.83 & 20 & 75 & 47.78 & 7.47 & 20 & 80 \\
\hline Job efforts & 0.45 & 0.24 & 0 & 1 & 0.46 & 0.23 & 0 & 1 \\
\hline
\end{tabular}

Source: SOEP v. 31 


\section{Results}

Figure 1 shows that women in highly qualified positions perceive higher WFC than men; the difference is significant at a 90 percent level. For information only, we also show the difference in WFC for white-collar employees excluding those in highly qualified positions. Also here, women perceive higher WFC than men, the difference between men and women is even higher than for the other sample. Furthermore, it is clear that WFC seems to be a stronger problem in highly qualified positions than other positions. The difference between these two groups of white-collar employees is significant $(\mathrm{p}<0.05)$. This underlines the importance of focusing on this group of people as special group with high permeability between occupational and private life.

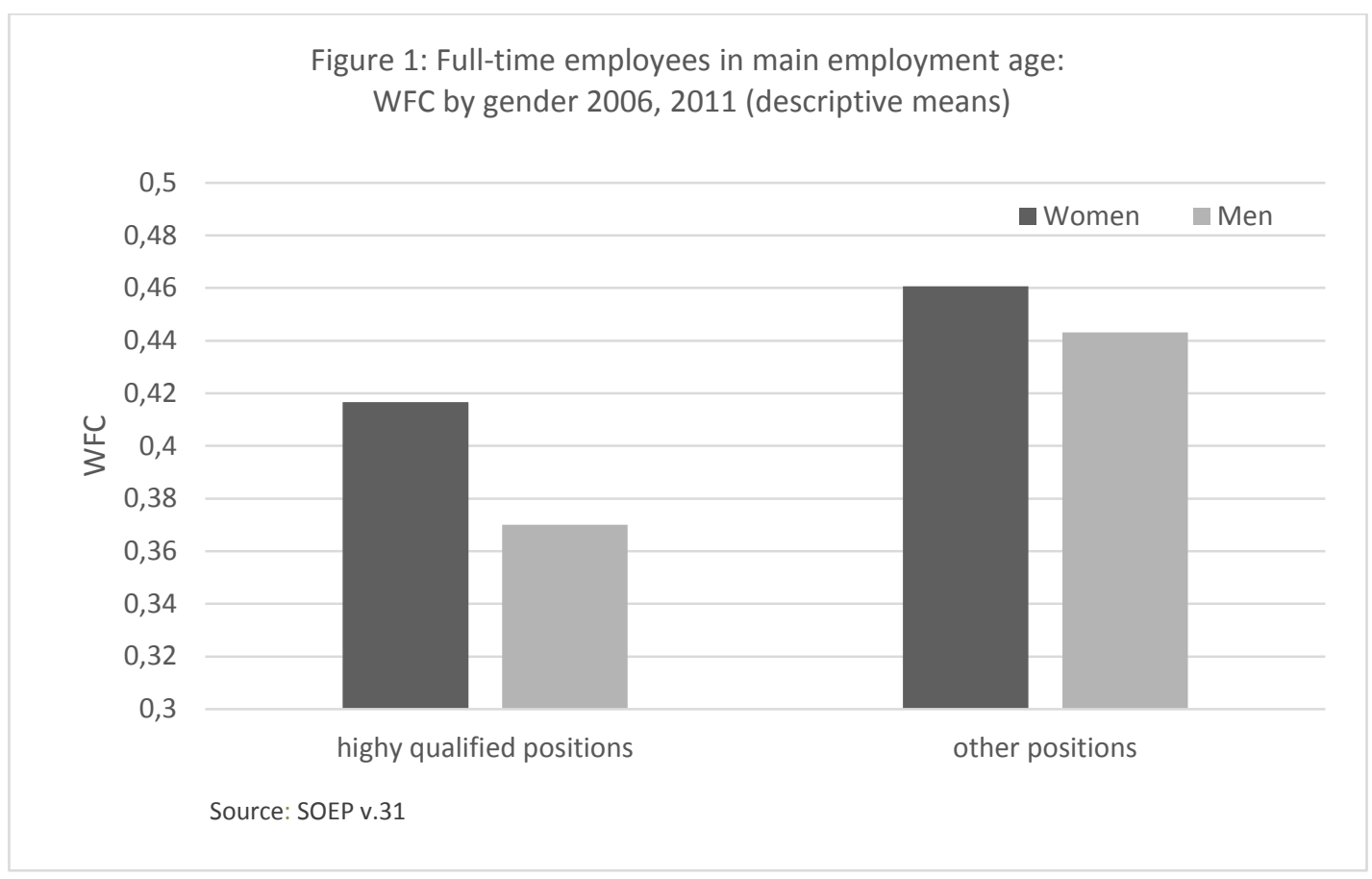

Table 2 shows the results of the multivariate OLS regression models with panel-robust standard errors, predicting WFC, together for women and men in highly qualified positions, including our control variables stepwise to see in how far the "gender effect" is mediated by our control variables (model 1 to model 4). Model 1, including structural control variables, the willingness to take risks and information on family responsibilities 
as control variables, shows that women perceive a WFC that is slightly higher than men. However, the difference is no more significant after including the willingness to take risks into the models (result without this variable not shown). Therefore, the significant difference in figure 1 can be explained by women’s higher risk aversion as compared to men. ${ }^{6}$ Model 2 includes information on job rewards. Here it shows that part of the rationale behind a higher WFC for women is the lower job rewards women receive. Especially the esteem component of job rewards is lower for women than for men in highly qualified positions (see table 1) and is strongly associated with a lower WFC at the same time. Therefore, as expected, the higher WFC for women is partly due to their lower positive resources that serve as a "counter pole." But since the coefficients in the gender difference are not significant in both models, although the result seems to go in line with our Hypothesis 3, it cannot be confirmed.

Model 3 shows that gender differences in WFC are somewhat underestimated when firm and occupational characteristics are not taken into consideration; the gender coefficient increases after including those variables to the models. This somewhat goes in line with our assumption that, in highly qualified positions, women and men are somewhat segregated in different occupations and workplaces with expected different opportunities to reconcile occupational and private life. For instance, women more often work in smaller firms, in the public sector, and are more often segregated in "women's occupations” (see table 1). But again, since the coefficient is still not significant, Hypothesis 4a is not confirmed. Interestingly, those occupational and firm characteristics do not show significant effects on WFC when looking on women and men together, the only significant effect is visible for vertical segregation. People with extensive managerial duties show higher WFC than persons with “only” managerial functions or highly qualified duties. 
Table 2: Determinants of Work-to-Family-Conflicts 2006, 2011

\begin{tabular}{|c|c|c|c|c|}
\hline & Model 1 & Model 2 & Model 3 & Model 4 \\
\hline \multirow[t]{2}{*}{ Women (ref.: Men) } & 0.0135 & 0.0086 & 0.0186 & $0.0272 *$ \\
\hline & $(0.0110)$ & $(0.0107)$ & $(0.0114)$ & $(0.0106)$ \\
\hline \multicolumn{5}{|l|}{ Family characterstics } \\
\hline \multirow[t]{2}{*}{ Married cohabitation (ref.: other) } & $0.0466 * * *$ & $0.0446 * * *$ & $0.0429 * * *$ & $0.0282 * *$ \\
\hline & $(0.0119)$ & $(0.0114)$ & $(0.0114)$ & $(0.0104)$ \\
\hline \multicolumn{5}{|l|}{ Age of youngest child in household (ref.: no child) } \\
\hline \multirow[t]{2}{*}{ Child under 7 in household } & $-0.0340 *$ & $-0.0294^{*}$ & $-0.0296 *$ & $-0.0241^{*}$ \\
\hline & $(0.0137)$ & $(0.0133)$ & $(0.0133)$ & $(0.0121)$ \\
\hline \multirow[t]{2}{*}{ Child from 7 to 16 in household } & -0.0143 & -0.0135 & -0.0147 & -0.0125 \\
\hline & $(0.0120)$ & $(0.0117)$ & $(0.0116)$ & $(0.0105)$ \\
\hline \multicolumn{5}{|l|}{ Job rewards } \\
\hline \multirow[t]{2}{*}{ Job security } & & $-0.0983 * * *$ & $-0.1022 * * *$ & $-0.0716 * * *$ \\
\hline & & $(0.0224)$ & $(0.0226)$ & $(0.0200)$ \\
\hline \multirow[t]{2}{*}{ Esteem } & & $-0.1267 * * *$ & $-0.1194 * * *$ & $-0.0616^{* *}$ \\
\hline & & $(0.0210)$ & $(0.0210)$ & $(0.0196)$ \\
\hline \multirow[t]{2}{*}{ Job promotion opportunities } & & -0.0043 & -0.0123 & 0.0173 \\
\hline & & $(0.0230)$ & $(0.0235)$ & $(0.0216)$ \\
\hline \multicolumn{5}{|l|}{ Firm and occupational characteristics } \\
\hline \multicolumn{5}{|l|}{ Economic industry (ref.: others services) } \\
\hline \multirow[t]{2}{*}{ Manufacturing industry } & & & 0.0158 & 0.0111 \\
\hline & & & $(0.0117)$ & $(0.0106)$ \\
\hline \multirow[t]{2}{*}{ Trade, hotels and catering. transport } & & & 0.0015 & 0.0006 \\
\hline & & & $(0.0155)$ & $(0.0142)$ \\
\hline \multicolumn{5}{|l|}{ Firm size (ref.: 19 or fewer employees) } \\
\hline \multirow[t]{2}{*}{20 to 199 employees } & & & 0.0091 & 0.0004 \\
\hline & & & $(0.0164)$ & $(0.0145)$ \\
\hline \multirow[t]{2}{*}{200 to 1999 employees } & & & 0.0019 & -0.0166 \\
\hline & & & $(0.0163)$ & $(0.0146)$ \\
\hline \multirow[t]{2}{*}{2000 employees or more } & & & -0.0106 & $-0.0295^{*}$ \\
\hline & & & $(0.0162)$ & $(0.0143)$ \\
\hline \multicolumn{5}{|l|}{$\begin{array}{l}\text { Share of women in occupation } \\
\text { (ref.: male-dominated occupation) }\end{array}$} \\
\hline \multirow[t]{2}{*}{ Mixed-gender occupation } & & & 0.0095 & 0.0072 \\
\hline & & & $(0.0103)$ & $(0.0094)$ \\
\hline \multirow{2}{*}{ Female-dominated occupation } & & & -0.0169 & -0.0178 \\
\hline & & & $(0.0168)$ & $(0.0154)$ \\
\hline \multirow{2}{*}{$\begin{array}{l}\text { Extensive managerial duties (ref.: } \\
\text { managerial functions/highly qualified duties) }\end{array}$} & & & $0.0339 *$ & 0.0024 \\
\hline & & & $(0.0157)$ & $(0.0145)$ \\
\hline Public sector (reference: private sector) & & & $-0.0222+$ & -0.0118 \\
\hline & & & $(0.0124)$ & $(0.0116)$ \\
\hline Time-based burdens in the job & & & & \\
\hline Actual working hours & & & & $0.0034 * * *$ \\
\hline & & & & $(0.0006)$ \\
\hline Job efforts & & & & $0.3342 * * *$ \\
\hline & & & & $(0.0187)$ \\
\hline Structural and personal characteristics & $\checkmark$ & $\checkmark$ & $\checkmark$ & $\checkmark$ \\
\hline Constant & $0.4693 * * *$ & $0.6730 * * *$ & $0.6699 * * *$ & $0.2737^{* * *}$ \\
\hline & $(0.0318)$ & $(0.0402)$ & $(0.0427)$ & $(0.0482)$ \\
\hline Adj. $R^{2}$ & 0.024 & 0.068 & 0.072 & 0.224 \\
\hline
\end{tabular}


In Model 4 we include information on time-based burdens in the job. Those variables have a high explanatory power, which is visible in the increasing adjusted r-squared, rising from 0.07 to 0.22 . This makes sense when we keep in mind that this control dimension captures an important part of WFC that is somewhat interrelated with the cognitive-based component of WFC (Greenhaus \& Beutell, 1985). Furthermore, the gender difference in WFC increases strongly after incorporating this information in the model. Therefore, since women are more often selected into work environments with somewhat lower job efforts (although gender differences are not very strong here) and considerably lower weekly work hours (see table 1), this selection effects underestimates WFC when it is not controlled for in the models. In other words, for women and men with the same weekly work hours and the same work efforts on the job, women show considerably higher WFC. This confirms Hypotheses 4b.

Figure 2 shows the predicted values of WFC for women and men based on the four models, computed when the other independent variables have mean values (margins, at means). It shows that the difference between women and men widens when firm and occupational variables are controlled (model 3) and is largest after taking time-based burdens at work into account (model 4). However, only in model 4 the gender difference is significant. 


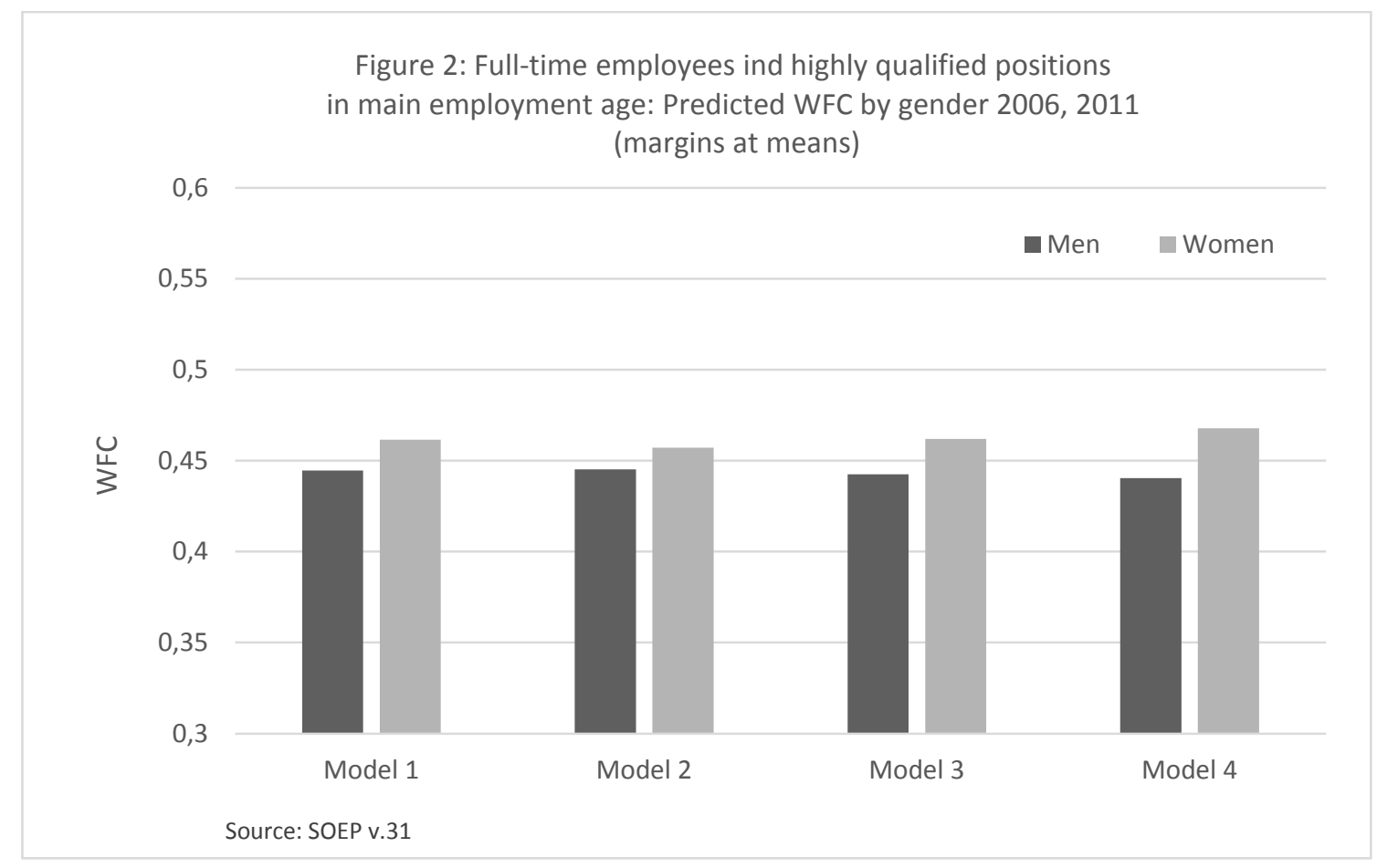

The other question we want to answer with our models is if family responsibilities are associated with WFC differently for women and men in highly qualified positions. For this, we run our model 4 separately for women and men to see if different coefficients emerge concerning the variables on family responsibilities. The results, in table 3 , show that only for men can we observe significant family effects on WFC: men, but not women, perceive particularly high WFC when they are married (the difference in the coefficients is significant). This is in line with the argument that WFC is particularly problematic for persons with family responsibilities. However, it contradicts our assumption that it is more problematic for women (Hypothesis 2). Furthermore, men with young children perceive lower, not higher WFC than those without children. Maybe we observe a positive effect of multiple role responsibilities, however surprisingly more for men than for women. 
Table 3: Determinants of Work-to-Family-Conflicts by Gender 2006, 2011

\begin{tabular}{|c|c|c|c|c|}
\hline & Women & & Men & \\
\hline \multicolumn{5}{|l|}{ Time-based burdens } \\
\hline Actual weekly working hours & 0.0014 & $(0.0012)$ & $0.0039 * * *$ & $(0.0007)$ \\
\hline Job efforts & $0.3666 * * *$ & $(0.0343)$ & $0.3236 * * *$ & $(0.0225)$ \\
\hline \multicolumn{5}{|l|}{ Family characteristics } \\
\hline Married cohabitation (reference: other) & -0.0043 & $(0.0167)$ & $0.0454 * * *$ & $(0.0131)$ \\
\hline \multicolumn{5}{|l|}{$\begin{array}{l}\text { Age of youngest child in household } \\
\text { (reference: No child in household) }\end{array}$} \\
\hline Child under 7 in household & 0.0161 & $(0.0292)$ & $-0.0366 * *$ & $(0.0136)$ \\
\hline Child from 7 to 16 in household & -0.0130 & $(0.0220)$ & -0.0167 & $(0.0121)$ \\
\hline
\end{tabular}

Firm and occupational characteristics ${ }^{\text {a }}$

Firm size (reference: under 20 employees)

$\begin{array}{lllll}20 \text { to } 199 & 0.0240 & (0.0252) & -0.0112 & (0.0176) \\ 200 \text { to } 1999 & 0.0087 & (0.0263) & -0.0228 & (0.0178) \\ 2000 \text { and more } & 0.0156 & (0.0259) & -0.0453 * * & (0.0172)\end{array}$

Share of women in occupation

(reference: male-dominated occupations)

Mixed-gender occupations

0.0451* (0.0208) -0.0013 (0.0107)

Female-dominated occupations

$\begin{array}{llll}0.0165 & (0.0266) & -0.0268 & \text { (0.0214) }\end{array}$

Structural characteristics

Personal characteristics

Job rewards

\begin{tabular}{|c|c|c|c|}
\hline Constant & $0.2525^{* *}$ & (0.0909) & $0.2956 * * *$ \\
\hline Adj. $R^{2}$ & 0.249 & & 0.221 \\
\hline $\mathrm{N}$ & 637 & & 1656 \\
\hline
\end{tabular}

When looking on the coefficients of our firm and occupational characteristics, different associations emerge for women and men. For a better interpretation, we show the predicted values of WFC as a function of the most striking firm and occupational characteristics with significant differences in the coefficients between women and men. Whereas men perceive lower WFC the larger the firm is, no significant difference is 
visible for women working in firms with different firm size (see figure 3). Therefore, large firms may offer some advantages for men in highly qualified positions, for example, high autonomy over the work, but not for women. This could be explained by "gendered organizational substructures" (Acker, 1990) with the norm of the male breadwinner model that are somewhat embedded in the structures of well-established, traditional organizations (large firms are often very old and established in former years where gender norms were still traditional) and offer some advantages for men, whereas women in those firms face certain boundaries.

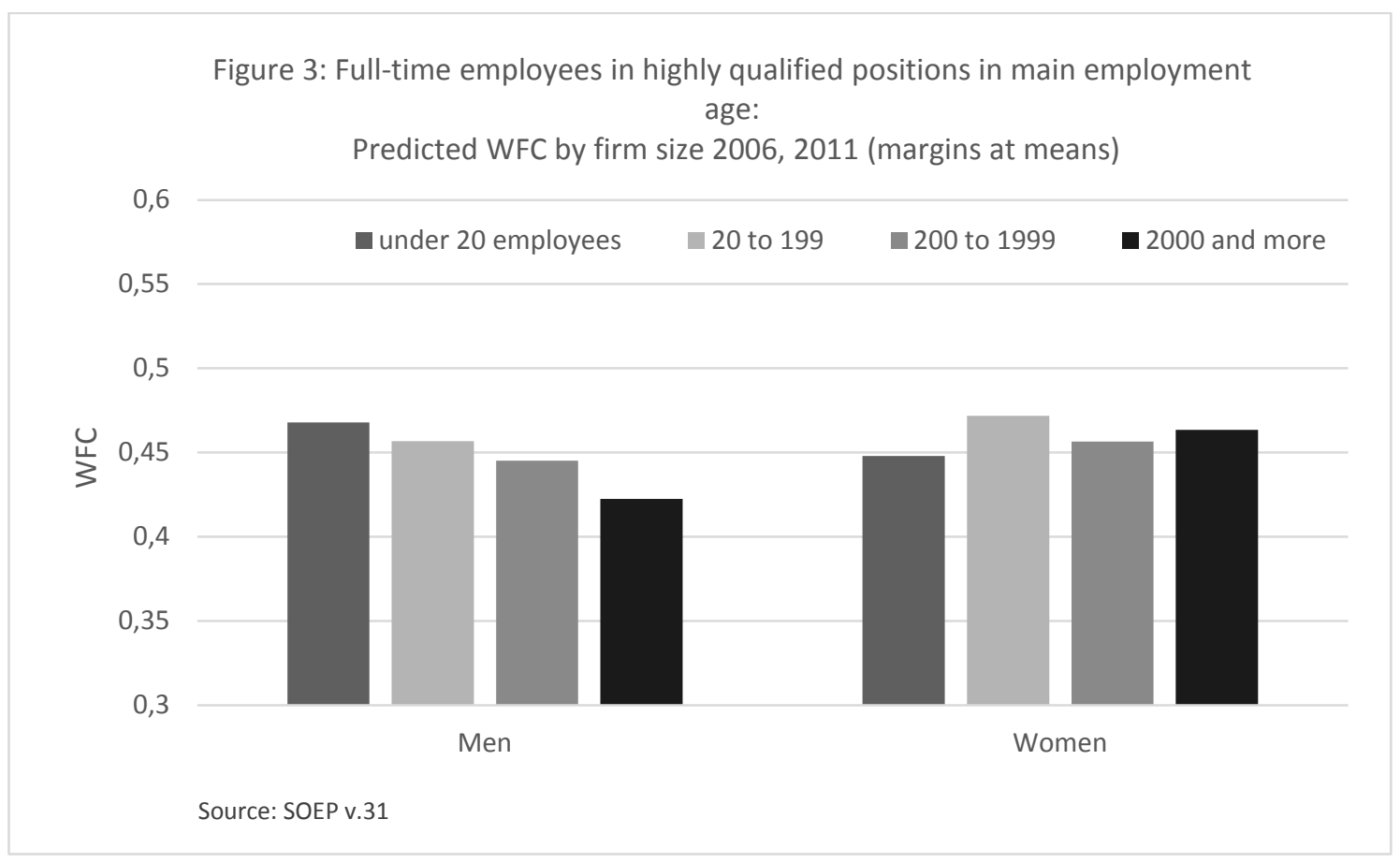

Furthermore, the gender label of the current occupation has significant associations with WFC, but only for women. Interestingly, contrary to the common assumption, women do not perceive the highest WFC in men's occupations, but rather in gender-balanced occupations. Assuming that this has something to do with different reconciliation opportunities in different occupations then those opportunities seem to be somewhat better in women's and men's occupations than those that are gender-balanced. Although we already controlled for time-based burdens in the job, it may be that the "occupational culture" in gender-balanced occupations is somewhat in line with the norm of the new 
“entreployee” in modern labor markets, requiring high flexibility and high permeability between both life spheres, which seems to be a problem especially for women. Since we do not observe a significant difference in WFC between women's and men's occupation, this indicates that it is not the case that in women's occupations the situation is best concerning reconciliation opportunities (figure 4). However, we should keep in mind that differences in WFC as a function of firm and occupational characteristics may also have something to do with selection effects (see section 5).

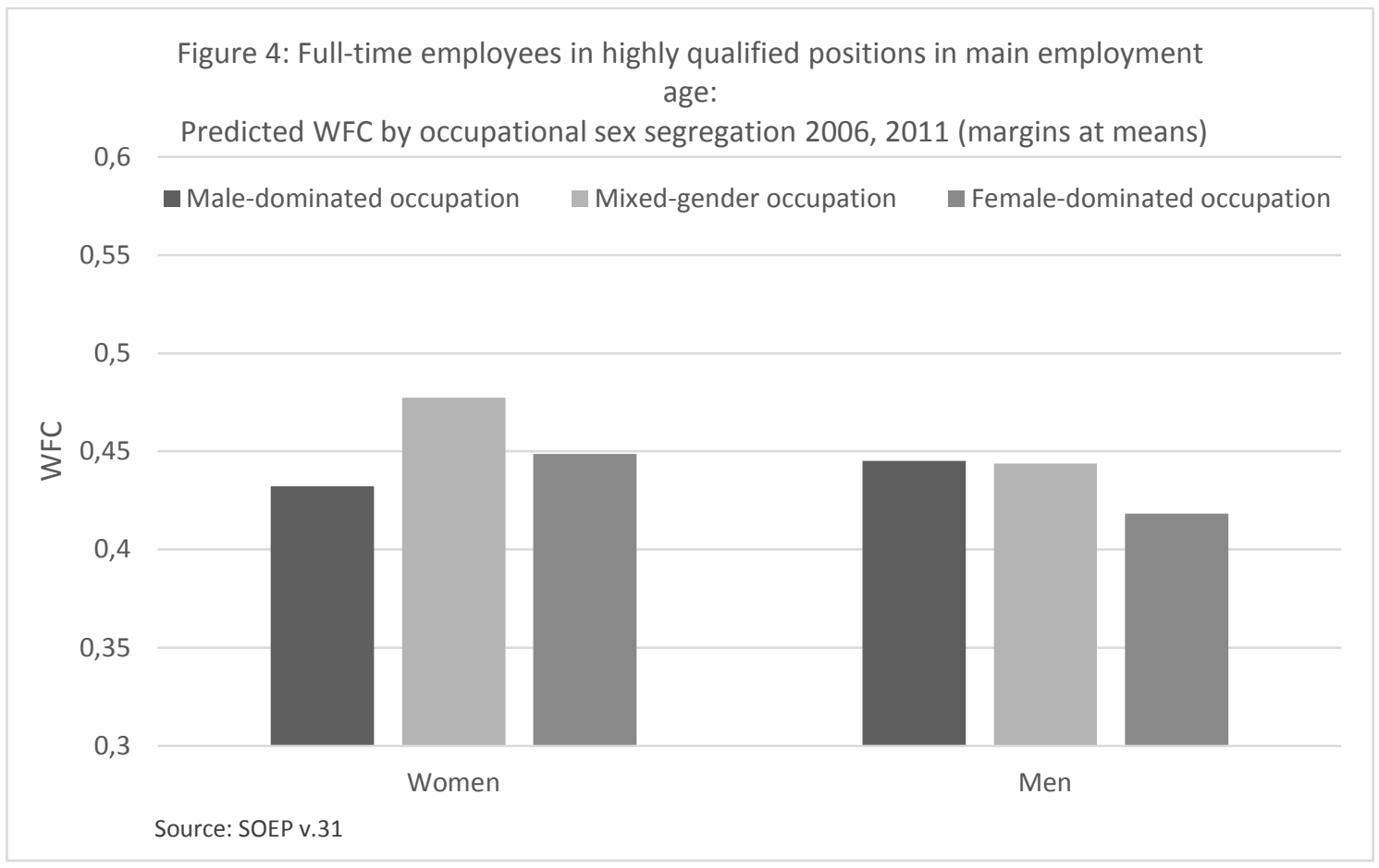

What is somewhat surprising is that the actual weekly working hours are associated with high WFC, but only for men. For women, other sources of conflict than the pure time-based ones, seems to play a more important role.

\section{Summary}

Concerning our hypotheses, the following can be concluded for full-time employees: the first hypothesis was that in highly qualified positions, women show higher WFC than 
men. This hypothesis could be confirmed in the description, with a small but significant difference between women and men. But in the multivariate model it is shown that this small gender gap is explained by women's lower willingness to take risks. The remaining low gender gap in WFC gets even lower after including job rewards into the models, since women receive lower job rewards than men on average and those rewards are strongly associated with WFC. The "Token-Status" of women in those positions may lead to discrimination at work, leading to lower job rewards and lower positive “resources” (as “counter poles” for job demands).

Furthermore, it was getting visible that differences between women and men in WFC is underestimated if organizational and occupational characteristics and, even more importantly, time-based burdens in the job are not controlled for in the models. The observation that women more often work in workplaces that offer better opportunities to reconcile both life spheres lowers their level of WFC. But when women and men working in similar workplaces with similar time-based working conditions are compared, these women experience significantly higher WFC than do the men. In other words, when the time-based sources of WFC are controlled for, differences in the cognitive component of WFC (serving as dependent variable in our models) between women and men come to light. This is an important result indicating that it is important to take those "structural" characteristics into account when examining gender differences in WFC - also in highly qualified positions where the situation is somewhat more "equal" between women and men. Therefore, in Germany, a traditional "gender arrangement” (Pfau-Effinger 2001) may lead to role conflicts for women in highly qualified positions, thus resulting in stress and cognitive rumination at home and, consequently, WFC.

However, concerning associations between family responsibilities and WFC, we observed mixed results: only for men do we observe increasing WFC for when they are 
married. Furthermore, decreasing effects of having young children on WFC were observed, again only for men. For women we did not observe any significant associations here. Here, we may observe a complex set of causes, balancing out positive and negative effects: on the one hand, we may have negative associations between family responsibilities and WFC in terms of double burdens and role ambiguities; on the other hand there may be positive experiences through multiple role responsibilities, thus resulting in a greater life fulfillment when both life spheres are successfully combined. This fits with the literature showing mixed results concerning the relationship between family responsibilities and WFC.

\section{Discussion}

Our study has some limitations. Firstly, although we already pooled two years in the SOEP, we still have relatively few women in highly qualified positions working fulltime in our sample. This is especially a problem concerning the variables on family responsibilities, where the numbers of women with young children is particularly low. Therefore, our results concerning family responsibilities and their effects on WFC should be taken with caution.

Secondly, we did not control for unobserved heterogeneity. For example, higher WFC for women may be the result of higher preferences for family-friendly working conditions. Above that, women with high career motivation and lower family orientation may select into those positions we observed, therefore underestimating the gender gap in WFC. In addition, relatively low WFC for women in men's occupations may be a result of selection of women with low preferences for family-friendly working conditions into those occupations. Although we do have panel data (two observation years), due to our relatively small sample and relatively little variation in our variables 
between only two years, running fixed effects regression models would lead to inefficient results (and also would not be the adequate method to show differences between time-stable characteristics, that is, men and women).

Nevertheless, our results show that also women in highly qualified positions have particular problems concerning perceived WFC in modern labor markets. This is important when it comes to the question of how to increase the share of women in highly qualified positions, leading to the conclusion that it is not enough to only quantitatively enlarging the amount, without taking into account also qualitative aspects of work at the same time (see also Pudrovska \& Karraker, 2014). It is important for men and women when it comes to the aspect of social sustainability in the context of modern labor markets. Sustainable human resource management in the context of labor markets can be seen as an appropriate, renewable handling with individual resources, so that not only work efforts are invested by employees, but that they get also something back and have time for regeneration (Neckel \& Wagner, 2014). This can be seen as sustainably efficient way to permanently maintain the efficiency of modern labor markets (ibid.). 


\section{References}

Acker, J. (1990). Hierarchies, Jobs, Bodies: A Theory of Gendered Organizations. Gender and Society, 4(2), 139-158.

Ahmad, A. S., King, E. B., \& Anderson, A. J. (2013). Effects of gender and parenting on work-life integration. In: D. A. Major \& R. J. Burke (eds.), Handbook of WorkLife Integration Among Professionals: Challenges and Opportunities (pp. 120-141). Northampton, MA: Edward Elgar Publishing.

Allen, T. D., \& Armstrong, J. (2006). Further Examination of the Link Between WorkFamily Conflict and Physical Health. The Role of Health-Related Behaviors. American Behavioral Scientist, 49(9), 1204-1221.

Allen, T. D., Herst, D. B. L., Bruck, C. S., \& Sutton, M. (2000). Consequences associated with work-to-family conflict: A review and agenda for future research. Journal of Occupational Health Psychology, 5(2), 278-308.

Apperson, M., Schmidt, H., Moore, S., \& Grunberg, L. (2002). Women managers and the experience of work-family conflict. American Journal of Undergraduate Research, 1(3), 9-15.

Baethge, M., Denkinger, J., \& Kadritzke, U. (1995). Das Führungskräfte-Dilemma: Manager und industrielle Experten zwischen Unternehmen und Lebenswelt. Frankfurt/New York: Campus.

Behnke, C., \& Meuser, M. (2003). Modernisierte Geschlechterverhältnisse? Entgrenzung von Beruf und Familie bei Doppelkarrierepaaren. In: K. Gottschall \& G. G. Voß (eds.), Entgrenzung von Arbeit und Leben. Zum Wandel der Beziehung von Erwerbstätigkeit und Privatsphäre im Alltag (pp. 285-306). München: Hampp.

Bellavia, G. M., \& Frone, M. R. (2005). Work-Family Conflict. In: J. Barling, E. K. Kelloway, \& M. R. Frone (eds.), Handbook of Work Stress (pp. 113-147). Thousand Oaks/London/New Delhi: Sage.

Bertrand, M., Kamenica, E., \& Pan, J. (2015). Gender identity and relative income within households. The Quarterly Journal of Economics, 130(2), 571-614.

Brines, J. (1994). Economic Dependency, Gender, and the Division of Labour at Home. American Journal of Sociology, 100(3), 652-688.

Busch-Heizmann, A., \& Bröckel, M. (2015). Die Auswirkungen geschlechts(un)typischer Berufstätigkeiten auf die Aufteilung der Hausarbeit in Partnerschaften. Kölner Zeitschrift für Soziologie und Sozialpsychologie, 67(3), 475-507.

Correll, S. J. (2004). Constraints into Preferences: Gender, Status, and Emerging Career Aspirations. American Sociological Review, 69(1), 93-113.

Cullati, S. (2014). The influence of work-family conflict trajectories on self-rated health trajectories in Switzerland: A life course approach. Social Science \& Medicine, 117, 25-33.

Eagly, A. H. (2003). More women at the top: The impact of gender roles and leadership style. In: U. Pasero (ed.), Gender - from Costs to Benefits (pp. 151-169). Wiesbaden: Westdeutscher Verlag.

Eccles, J. S. (1987). Gender Roles and Women's Achievement-Related Decisions. Psychology of Women Quarterly, 11(2), 135-172.

Esping-Andersen, G. (1990). The Three Worlds of Welfare Capitalism. Princeton, NJ: Princeton University Press. 
Federal Statistical Office. (1992). Klassifizierung der Berufe - Systematisches und alphabetisches Verzeichnis der Berufsbenennungen. Ausgabe 1992. Stuttgart: Metzler-Poeschel.

Federal Statistical Office. (2012). Qualitätsbericht - Mikrozensus 2011. Wiesbaden: Federal Statistical Office.

Fietze, S., Holst, E., \& Tobsch, V. (2011). Germany's Next Top Manager: Does Personality Explain the Gender Career Gap? Management Revue: The International Review of Management Studies, 22(3), 240-273.

Frey, M. (2004). Ist der „Arbeitskraftunternehmer“ weiblich? „Subjektivierte“ Erwerbsorientierungen von Frauen in Prozessen betrieblicher Diskontinuität. Arbeit, 13(1), 61-77.

Glass, J. (1990). The Impact of Occupational Segregation on Working Conditions. Social Forces, 68(3), 779-796.

Greenhaus, J. H., \& Beutell, N. J. (1985). Sources of Conflict between Work and Family Roles. The Academy of Management Review, 10(1), 76-88.

Greenhaus, J. H., \& Parasuraman, S. (1987). A Work-Nonwork Interactive Perspective of Stress and Its consequences. Journal of Organizational Behavior Management, 8(2), 37-60.

Holst, E., Busch-Heizmann, A., \& Wieber, A. (2015). Führungskräfte-Monitor 2015. Update 2001-2013. DIW Politikberatung kompakt 100/2015. Berlin: DIW.

Huber, P. J. (1967). The Behavior of Maximum Likelihood Estimates under NonStandard Conditions. Proceedings of the Fifth Berkeley Symposium on Mathematical Statistics and Probability, 1, 221-233.

Jacobs, J. A. (1989). Revolving Doors. Sex Segregation and Women's Careers. Stanford, California: Stanford University Press.

Kanter, R. M. (1977). Some Effects of Proportions of Group Life: Skewed Sex Ratios and Responses to Token Women. American Journal of Sociology, 82(5), 965-990.

Kotthoff, H. (2001). Zwischen Selbstausbeutung und Selbstverwirklichung : Wandlungen im Arbeitsmodell hochqualifizierter Angestellter. Arbeitspapiere / Universität Bremen, ZWE Arbeit und Region(44).

Marini, M. M., \& Brinton, M. C. (1984). Sex Typing in Occupational Socialization. In: B. F. Reskin (ed.), Sex Segregation in the Workplace. Trends, Explanations, Remedies (pp. 192-232). Washington, DC: National Academy Press.

McGinnity, F., \& Calvert, E. (2009). Work-Life Conflict and Social Inequality in Western Europe. Social Indicators Research, 93(3), 489-508.

Moosbrugger, J. (2012). Subjektivierung von Arbeit: Freiwillige Selbstausbeutung. Ein Erklärungsmodell für die Verausgabungsbereitschaft von Hochqualifizierten. 2., erweiterte Auflage. Wiesbaden: Springer VS.

Neckel, S., \& Wagner, G. (2014). Burnout. Soziales Leiden an Wachstum und Wettbewerb. WSI-Mitteilungen(7), 536-542.

Peuckert, R. (2012). Arbeitsteilung zwischen den Geschlechtern: Nach wie vor geringe Beteiligung der Männer an Haus- und Familienarbeit. In: R. Peuckert (ed.), Familienformen im sozialen Wandel. 8. Auflage (pp. 475-506). Wiesbaden: Springer VS.

Pfau-Effinger, B. (1998). Gender cultures and the gender arrangement: A theoretical framework for cross-national comparisons on gender. Innovation: The European Journal of Social Science Research, 11, 147-166.

Pongratz, H. J., \& Voß, G. G. (2003). From employee to 'entreployee': Towards a 'selfentrepreneurial' work force? Concepts and Transformation 8(3), 239-254.

Pudrovska, T., \& Karraker, A. (2014). Gender, Job Authority, and Depression. Journal of Health and Social Behavior, 55(4), 424-441. 
Ridgeway, C. L. (2001). Gender, Status, and Leadership. Journal of Social Issues, 57(4), 637-655.

Ruderman, M. N., Ohlott, P. J., Panzer, K., \& King, S. N. (2002). Benefits of Multiple Roles for Managerial Women. Academy of Management Journal, 45(2), 369-386.

Sauer, C. (2012). Entgrenzung - Chiffre einer flexiblen Arbeitswelt - Ein Blick auf den historischen Wandel von Arbeit. In: B. Badura, A. Ducki, H. Schröder, J. Klose, \& M. Meyer (eds.), Fehlzeiten-Report 2012: Gesundheit in der flexiblen Arbeitswelt: Chancen nutzen - Risiken minimieren (pp. 3-13). Berlin Heidelberg: Springer-Verlag.

Schieman, S., \& Glavin, P. (2016). The Pressure-Status Nexus and Blurred WorkFamily Boundaries. Work \& Occupations, 43(1), 3-37.

Schiemann, S., Whitestone, Y. K., \& Van Gundy, K. (2006). The Nature of Work and the Stress of Higher Status. Journal of Health and Social Behavior, 47(3), 242-257.

Siegrist, J., Wege, N., Pühlhofer, F., \& Wahrndorf, M. (2008). A short generic measure of work stress in the era of globalization: effort-reward imbalance. International Archives of Occupational and Environmental Health.

Voß, G. G. (1998). Die Entgrenzung von Arbeit und Arbeitskraft. Eine subjektorientierte Interpretation des Wandels der Arbeit. Mitteilungen aus der Arbeitsmarkt- und Berufsforschung, 31(3), 473-487.

Wagner, G. G., Frick, J. R., \& Schupp, J. (2007). The German Socio-Economic Panel Study (SOEP) - Scope, Evolution and Enhancements. Schmollers Jahrbuch, 127(1), 139-169.

West, C., \& Zimmerman, D. H. (1987). Doing Gender. Gender and Society, 1(2), 125151.

White, H. (1980). A Heteroskedasticity-Consistent Covariance Matrix Estimator and a Direct Test for Heteroskedasticity. Econometrica, 48(4), 817-830.

White, M., Hill, S., McGovern, P., Mills, C., \& Smeaton, D. (2003). 'Highperformance' Management Practices, Working Hours and Work-Life Balance. British Journal of Industrial Relations, 41(2), 175-795.

Wieber, A., \& Holst, E. (2015). Gender Identity and Womens' Supply of Labor and Non-Market Work: Panel Data Evidence for Germany. DIW Discussion Paper No. 1517. Berlin: DIW.

Wyman, O. (ed.) (2016). Women In Financial Services. http://www.oliverwyman.com/content/dam/oliverwyman/global/en/2016/june/WiFS/WomenInFinancialServices_2016.pdf [24.01.2017] 


\section{Endnotes}

${ }^{1}$ We focus on work-to-family conflicts and not the opposite direction (family-to-work conflicts) and do not investigate the health effect of work-to-family conflicts. Although this would be interesting and important, it would expand the space and the focus of the present paper.

${ }^{2}$ A "culture is masculine when the population displays a preference for achievement, heroism, assertiveness, and the material rewards for success. A masculine society is competitive rather than consensual. A feminine culture, according to Hofstede, prefers cooperation, modesty, caring for the weak, and quality of life” (Wyman, 2016, p. 54). The study finds a negative correlation, for example, between cultural masculinity and female representation on financial services firms’ Executive Committees.

${ }^{3}$ Although Kotthoff (2001) points out that those advantages more and more decline with the societal changes.

${ }^{4}$ Although assumptions and empirical results concerning this arguments are mixed (e.g., Glass, 1990).

${ }^{5}$ Here we use the ISCED classification, category 6 (higher education).

${ }^{6}$ See also Fietze et al. (2011) for gender differences in risk aversion in highly qualified positions. 